\title{
Taiwan and the Globalization of Puer Tea: The Role of the Taste of Aging
}

\author{
Shuenn-Der Yu \\ Institute of Ethnology, Academia Sinica, Taipei, Taiwan
}

\begin{abstract}
Puer tea was produced in Yunnan, consumed mainly in Guangdong, Hong Kong, and Tibet, but became a fad in Taiwan during mid-1990s, which later spread back to Hong Kong, GuangDong, Yunnan, the entire China, and also to Korea, Japan and Southeast Aisa. This paper analyzes how and why Taiwan, which knew very little of Puer tea before 1990s, has played such an important role in the globalization of Puer tea. I argue that it's not only the historical contingencies, especially Hong Kong's returning to China in 1997, that gave Taiwan the opportunity to import aged Puer tea that had stocked in Hong Kong for years; more importantly it was Taiwan's sophisticated tea tasting culture that provided the fertile ground for the development of a taste considered valuable and hence a fad for aged Puer. This taste of aging tea has since come to be the foundation of Puer tea market as the value of Puer has become to be evaluated on the degree of aging and Puer has been traded as though futures or stocks, resulting in the craze for this once little-known commodity and the globalization of its consumption. The case of Puer tea suggests that as we follow Appadurai's suggestion and pay attention to five cultural flows-ethnoscapes, mediascapes, technoscapes, financescapes and ideoscapes—when studying globalization, we may benefit also from focusing on the "sense-scape," or the intense cultural flow of sensory information around the world.
\end{abstract}

Keywords: Puer tea, globalization, sense-scape, Taiwan

Before the 1990s, only a few Taiwanese had tasted Puer tea. Even when drinking and collecting Puer had become a fad in the later 1990s, it was still not a popular commodity among the general public. Nonetheless, Taiwan's relatively small market played a key role in the globalization of Puer consumption, which saw Puer go from a tea whose appeal had been limited to Hong Kong and China's Guangdong Province to the most sought-after tea by Chinese and later by Asians. How and why was Taiwan able to play such an important part in Puer's globalization, and what we can infer from this interesting case? These questions are the focus of this paper.

Puer tea is produced in Yunnan, China. Before the mid-1990s, Taiwanese people's experience of Puer was mostly limited to the Puer-chrysanthemum tea served in Hong Kong-style teahouse restaurants. It was customary for Taiwanese to follow the Hong Kong habit of ordering this ammonia-like earthy tea to go with the greasy snack dishes. The dried chrysanthemum flowers were added to the dark Puer to tone down its special flavor, which was often described as “stinky” (choupu 臭脯) by Taiwanese consumers. They even referred to Puer as "choupu tea" in the 1990s.

Shuenn-Der Yu, Ph. D., research fellow, Institute of Ethnology, Academia Sinica.

Correspondence concerning this article should be addressed to Shuenn-Der Yu, Institute of Ethnology, Academia Sinica, Nankang, Taipei, Taiwan. 
Cultivating a taste for aged tea did not come easy for the Taiwanese, who have long been used to drink partly fermented Woolong teas. Tea appreciation in Taiwan very much emphasizes fragrances. This was especially true in the 1990s when the high-mountain Woolong tea became popular. Its light fermentation and roasting and its special fragrance all made it unique among Woolong teas, and came to represent the tasting notes and fragrances especially preferred among Taiwan's tea connoisseurs. Hence the acceptance of a tea having no significant fragrance was really an interesting phenomenon, which involved a significant transformation of tea tasting style expanding towards tasting categories Taiwanese were not familiar with.

From the mid-1990s, thanks to the great efforts of Taiwanese tea merchants who developed a taste for aged Puer and successfully educated their customers to appreciate its special flavor, this tea gradually gained acceptance among tea lovers, which drove up the price significantly in a few short years. By 2000, the enormous numbers of aged rounds (large compressed cakes) and bricks of tea being imported from Hong Kong had made Taiwan the most significant Puer tea market outside Hong Kong. By the mid-2000s, tea rounds that had aged for 50 years were being sold for as high as half a million NT (equivalent to around US\$19,000). The Puer tea fad was an entirely new phenomenon in Taiwan's tea market, and its like had not been seen before in the world tea market, either. This case is also distinctive because the fad for aged Puer in Taiwan quickly spread back to the major consumption areas of Hong Kong and Guangdong, then to production sites in Yunnan, and across all of China, and then to Japan, Korea, Southeast Asia, the United States, and Europe (e.g., France and Poland). That Taiwan, which had little connection to Puer tea before the 1990s and represented a relatively small market, could have such an impact on the fate of this commodity is quite striking.

Taiwan media and tea traders in Kunming tend to explain the emergence of the Puer fad in terms of Taiwanese merchants' ability to “stir up the market” (chaozuo 炒作). Puer’s penetrate into the Taiwan market did involve a number of successful promotional strategies, e.g., organizing tea events and publishing journals and books that introduced Puer to the public, which successfully framed the tasting of aged Puer as part of Taiwan's refined tea tasting culture. They classified tea produced by private firms in the early Republican era as "antique tea" and made authenticity a central concern at tastings. Since the "authentic tea" was limited, at least in theory, the urge to stock up for future consumption pushed Puer lovers and merchants alike to hoard Puer, which explained its increased market price and sales as collecting became competitive at this historical moment. The chaozuo theory also stressed how Taiwanese merchants advertised Puer's medicinal attributes and the important role such advertisements played in the Puer tea fad.

However, it is difficult to explain Taiwan's Puer fad solely in terms of its effective promotion by Taiwanese merchants. For one thing, it does not account for how this new commodity, once widely described as having a stinky flavor, came to be accepted by Taiwanese consumers. Nor does the chaozuo theory tell us how consumers thought about Puer and why their understanding of it was able to drive a desire to collect aged Puer at the high prices it began to fetch. We all know it is not possible to create a fad by simply promoting a thing. Using chaozuo to describe the Puer phenomenon implies that the tea's market value (price) is higher than its real value, but does not tell us how to evaluate Puer's value or the speedy development of the drive to collect it. The chaozuo account does not consider the fact that Taiwan's promotional strategies were not similarly implemented in mainland China ${ }^{1}$ and does not explain how Taiwan's Puer fad actually influenced China's Puer consumption and production. We need to get deep into each of these connections in the Puer

\footnotetext{
${ }^{1}$ Guangdong and Yunnan consumed mainly the specially fermented “cooked” Puer tea developed only after mid-70s, instead of the aged "raw" Puer, which was produced without this special fermentation process and has been preferred by Taiwanese.
} 
craze, and especially its globalization process, to really understand this fascinating chapter in the world history of tea.

The globalization of Puer tea consumption involves diverse aspects other than the various actors-tea merchants, consumers, and governments—engaging at different times and places. There were also the different strategies for promotion and investment, and the process of globalization itself presents special complications. Recent globalization studies have framed consumption in terms of "globalization" versus "localization." Anthropologists are particularly interested in localizing phenomena within globalization processes. James Watson's 1997 study of McDonaldization is one of the best examples. Most studies pose "globalization from the West" versus "localizations in the rest of the world" when examining the globalizing process (Bester, 2001). Some efforts have been made to avoid using this framework, but cannot but being strained within the relationship between these two poles (Zheng, 2011). The Puer case forces us to reconsider this framework. Puer tea was originally produced in Yunnan mainly for local consumption. During Qing times, it became a tribute item offered to the Qing imperial household and high officials in Beijing; it was also exported to Tibet, Guangdong, and Hong Kong, but never gained a national reputation as one of China's famous teas. It gained a whole new life, however, when it entered the Taiwan market, where it not only became a high-priced commodity and collectible item, but also made Taiwan a leading center of Puer consumption. From the perspective of globalization studies, the Puer phenomenon complicates and confounds the "globalization versus localization" framework.

With the emergence of Puer in Taiwan, we see a new tasting category, the "taste of aging," being established through fast exchanges of information and flows along Puer's commodity chain, to become the new standard of value in evaluating the tea. Within its consumption areas, the taste of aging has become taken for granted as marker of value for Puer. A thirty-year-old tea round is thought of as "naturally" commanding a higher price and possessing a more desirable flavor than younger tea. In other words, with globalization, Puer not only spread to various parts of the world and became a well-known tea, it also established the idea that tea, a supposedly perishable commodity, when stored for long periods of time can be expected to possess better flavor and higher value. Like red wine, stockpiled Puer should increase in value, and tea at different ages should enjoy different prices. As East Asia, Southeast Asia, and parts of Europe began to go crazy for Puer, collecting the tea for its "taste of aging" and its future value became both a style of consumption and an investment strategy.

That the aged flavor of the tea has become a category of appreciation and a standard of value has long-term implications for the Puer market. First of all, the flavor for which Puer is famous, its chennian (陳年, aging), has directly contributed to its resurgence. Due to local chaos in the late Qing years, Yunnan officials stopped offering Puer as tribute to the royal family. Its consumption was limited to only a few areas, mainly Guangdong, Hong Kong, and Tibet. Puer production in the "Six Tea Mountains," the most famous Puer production area in Qing times, significantly declined in the early Republican era. All private tea firms were confiscated after New China was established, and Yunnan's tea production was transferred to a few state firms whose main mission was manufacturing black tea for export. It was not until the "taste of aging” was identified and promoted in Taiwan as a delicacy deserving of appreciation that we saw a revival of Puer production and market expansion in the mid-1990s. As the stores of aged tea gradually decline due to continuous consumption, the potential value from long-term stockpiling of newly produced Puer continues to attract numerous collectors. This greatly pumps up the amount of Puer tea being traded (but not drunk) and makes new Puer tea an ideal 
target for investing. With the popularization of the "taste of aging," the Puer market has been greatly invigorated. Age becoming the key factor in assessing Puer's value has encouraged people to trade the tea like stocks or futures. And as this flavor category has come to play such an important role in the globalization of Puer's commodity chain, just how to reproduce the "right" aging and how to stockpile new tea to duplicate the flavor of the aged tea that hit the market in the 1990s has become an important concern. Since most consumers today have not actually tasted the "antique tea" that gave rise to the Puer fad in the mid-90s, they all expect that their stockpiled tea will eventually develop an appreciable and valuable flavor. This collective effort to reproduce the "taste of aging" has been based on a communal imagination of Puer's unique flavor, helping Puer to spread from rather limited consumption areas to various parts of the world in less than 20 years.

\section{The Development of the Puer Fad}

Tea was one of the most important commodities produced in Yunnan. Beginning in the Tang dynasty, Yunnan tea was exported to the central plains of China (zhongyuan 中原) and Tibet. The term pucha (“pu” tea) first appeared in Xie Zhaozhi's Dianlue, a work compiled during Wanli reign era of the Ming dynasty. In the late Ming, when Puer Prefecture became the most important trading center for Yunnan teas, the tea produced in Yunnan was generally known as "Puer tea." Puer tea was much preferred by the Qing royal household. The Yungzheng emperor established Puer Prefecture to regulate trade and select the top-grade tea to be submitted as tribute to Beijing. Because it was preferred by the Qing royal household, Puer consumption in the capital city was limited to the royal family and high officers. Puer's most important general trade and consumption areas remained Tibet, Guangdong, and tiny Qing-era Hong Kong. Puer did not become popular in Yunnan before 2000. Yunnan people mostly drank green tea; Puer was produced mainly for export.

In the late 1970s, a few Taiwanese tea merchants who brought over mainland Chinese teas from Hong Kong also imported small amounts of Puer tea to Taiwan. Hong Kong tea merchants asked them to introduce Puer to the Taiwanese along with the Fujian—and Guangdong—produced partly fermented teas they had been carrying. Since Taiwan and China were hostile to each other at that time, the Taiwanese merchants could only bring the teas they could fit in their luggage when traveling back from Hong Kong. Another channel was by way of sailors, who smuggled Puer tea on consignment for certain specialty stores. Some Taiwanese who were curious about Chinese merchandise would visit these so-called ueituohang stores (委託行).

Hong Kong tea merchants were already aware that aged Puer tea had a better flavor than that of newly produced teas. They used the term jiachuan Puer (家傳普洱, Puer inherited over generations) for the aged tea in hopes of selling it to Hong Kong people at slightly higher prices. When this attempt did not succeed, the merchants transferred their hopes to the Taiwan market. The best-known Puer, the so-called "red-ink" (hongyin 紅印) tea produced by Yunnan's first state-owned tea firms during late 1940s and mid-1950s, was imported into Taiwan under this scheme.

Still, it took quite a long while for Taiwanese tea lovers to accept the aged Puer. According to one Taiwanese tea merchant who imported Puer as early as the late 1970s, it was difficult at the time to sell a round of red-ink tea that he bought for 800 NT in Hong Kong for 1200 NT. He remembered that he often had to really prod and persuade his colleagues or customers to purchase one. No one could have imagined that 30 years later a round of red-ink tea would be auctioned for one million RMB.

It also took time for the "taste of aging” flavor category to become established. Taiwanese tea lovers who had been accustomed to Woolong teas found Puer's taste hard to accept. As mentioned above, Taiwanese are 
very particular about tea fragrances and often take great care in selecting the utensils and steeping method to bring out their preferred aromas. They found aged Puer's lack of fragrance disappointing and so their cultivating an appreciation for the taste of aged Puer required significant adjustments. ${ }^{2}$

The period between the late 1970s and early 1990s can be characterized as a stage of groping. As Hong Kong's style of tasting aged Puer gradually spread to Taiwan, the Taiwanese increasingly accepted Hong Kong emphasis on tasting the water quality (shuixing 水性) of Puer. They began to use teapots with loose clay texture to brew Puer's smooth mouth feel (kougan 口感), instead of those made of delicate but solid clays used for high-fragrance Woolong teas. Moreover, as Puer gained in stature with the local tea community, Taiwanese tea connoisseurs also began to establish their own style and standards for its appreciation. Taiwan's market for aged Puer tea gradually emerged from this groping and sent prices for aged Puer tea skyrocketing in the late 1990s. Despite those who had entered the Puer market early withdrawing out of worry over a "Puer bubble," different investors continued to enter the Puer trade and this kept the Puer market prosperous.

Hong Kong's handover to China is another key element in this story. Uncertainty regarding Hong Kong's economic future at that time led some tea merchants to sell off their entire tock. A number of Taiwanese merchants saw the tea's market potential and took the opportunity to import large amounts of aged Puer. Some Hong Kong merchants wondered why their Taiwanese counterparts were so brave, if not irrational, about importing such quantities of the aged tea they had difficulty selling in Hong Kong. It turned out that Taiwanese merchants' instincts were spot-on. Puer's initial success in the Taiwan market drove Taiwanese merchants searching for more of the stuff not only in Hong Kong but also in Southeast Asia where Puer had been exported for many years. Large quantities of good quality aged tea had been accumulated in Taiwan by the 2000s, making Taiwan the center of the new Puer tea fad. Taiwan's leadership in the fad thus grew out of a whole string of circumstances. No wonder many have agreed that Taiwan's role can be described as a "historical coincidence."

Another factor was that the Puer tea aged over 30 years had been stored in Hong Kong's old tea firms, rather than in production areas of Yunnan or the main consumption areas across Guangdong. The ability to age tea for later sale involves a very basic issue-the economic prosperity that allows the tea to be stockpiled against the urge to cash in. Stockpiling may induce appreciation of Puer but it relies on non-circulation to create market value. If there were not significant disparities between the economies of Hong Kong and Yunnan from the 1950s up to at least mid-90s, it would not have been feasible for Hong Kong merchants to stockpile Puer tea without worrying about capital lying idle. Lacking this fundamental difference between the two economic systems, the Puer tea fad could never have emerged.

The knowledge that aging positively affects Puer's taste has existed for decades, but its origin is hard to pin-point. There are stories about teashops in Hong Kong that stored good tea in warehouses for future consumption, which explains why we have quite a lot of aged Puer today (Deng, 1995). However, there is no evidence that Hong Kong teashops in any systematic way stockpiled tea before the Puer fad of the mid-1990s. Tea merchants in the Kunming wholesale markets often use the saying "the grandfather manufactures tea for the grandson to sell” to suggest that aged Puer had been a major commodity among early private firms and the taste for aged Puer tea existed decades before today's fad. Some others, for example, the Taiwanese teashop owner Zhou Yu (in his lecture), also tell a story about the Red Guard burning Puer stored in state-owned tea

\footnotetext{
${ }^{2} \mathrm{Yu}$ (2006) provides a detailed analysis of the transformation of tasting styles induced by the consumption of Puer tea in Taiwan.
} 
factories during the Cultural Revolution to explain why there is no aged Puer tea in Yunnan. But the former account was likely invented quite recently and we can find no evidence for the latter.

What we can be certain of is that the aging of Puer tea in a systematic manner is a recent practice. The first Yunnan state-owned tea factory was established in the last few years of Sino-Japanese war. The Menghai tea factory imported machines to manufacture black tea for export. In the 1950s and 1960s, black tea produced in Yunnan was an important source of foreign exchange for the Chinese government. Lei Pingyang's research on the Menghai tea factory also shows that before 1964 Puer tea represented only a small percentage of Menghai's production (2003). Also, under the planned economy model, the production at state-owned factories was determined by government orders received, not by markets; only with reforms, when the rigid planed economy was dropped nationally in 1995, was it possible to create surplus production that could be intentionally stockpiled as an investment. Today most of the so-called aged Puer seen in Kunming's wholesale markets is 15 years old or under, rather than the "authentic aged Puer" that had been accidently stored in Hong Kong, which often had been warehoused at least 30 years.

Media also gave the Puer fad an important push. The first Puer book, titled Puer Tea, by Deng Shihai, a professor at Taiwan Normal University, was published in 1995. This book can be said to have defined the major issues around Puer for the next 10 years and remains the most important Puer book today. It provides in-depth introductions to Puer's history and tasting. Deng not only teaches readers what to taste for when drinking a cup of Puer; he even goes into details about the character of each aged Puer round or brick he collected. The great popularity of Deng's book encouraged the subsequent publication of other Puer books, to the extent that tens of them appeared each year in the early 2000s. The first Puer journal, Puer and the Art of Teapots, came out in 2002 in Taiwan. This monthly journal provides both production and consumption information about Puer; it even has a section analyzing the Puer market and teaches readers how to invest in kinds of Puer, just like analysts teaching consumers how to choose stocks. Beginning in the early 2000s, most Taiwanese and Chinese tea websites also included a special Puer section that provided all kinds of information, from histories of individual tea firms or teas, to discussion and debate over Puer issues. No other tea has attracted so much attention.

These historical contexts have certainly facilitated Puer tea's success. Puer has changed from a product manufactured in the southwest borderland and traded along China's periphery to a global commodity commanding considerable prices and being traded like stocks and futures. Probably no other tea can claim such an astonishing life history.

\section{Why Taiwan?}

Why was Taiwan, a newly developed Puer market, able to become the most important player in the aged Puer fad of the mid-1990s? Or, stated differently, why was the flavor of aged Puer developed by tea aficionados in Taiwan, rather than in Hong Kong, where the aged Puer tea had long been stockpiled? Why did Taiwan come to lead in Puer consumption and set market trends from the mid-1990s to mid-2000s?

Stockpiling tea for long periods to develop its unique flavor has clearly been practiced for a long time, but we do not know from historical records whether it was widely practiced. Li Yuanyang's (1497-1580) Jiajing Dali Fuzhi (嘉靖大理府誌) published in 1573, states, “Diancang mountain produces tea; its tea tree can grows as tall as twenty feet. Diancang tea's quality is not inferior to that of Yangxian. The longer the tea is stored, the better it tastes.” Diancang is a famous mountain in Dali, Yunnan. Although we do not have evidence showing 
that tea produced at that time was anything like Puer, Li Yuanyang’s statement does demonstrate that people in Ming times knew storing tea away would produce a flavor of better quality than newly processed leaf.

Nonetheless, we found no clear evidence that consumers in Ming or Qing times emphasized the age of their teas as much as we do today; "aged” does not seem to have been a significant tasting category. There are no records about intentionally stockpiling Puer to enjoy the flavors specially developed through long-term aging. When Puer tea began to be offered as local tribute in the tenth year of the Yungzheng reign era (1729), it was like other tribute teas offered to the royal household, strongly emphasizing the "fresh and fragrant" taste developed from newly picked tea leave tips. The Qing imperial household was especially fond of the tea produced in Mansong village on Yibang Mountain, whose tea was said to be sweeter, more fragrant, and more flavorful—at its best when new and fresh (Deng, 1995). In the famous Qing novel The Dream of the Red Chamber, Cao Xueqin's “steeping a bowl of Puer tea" image is probably the most quoted description of how Puer tea was prepared in Qing times, allowing us to imagine how it was consumed. ${ }^{3}$ However, Cao only pointed out that the kind of Puer was called nuercha 女兒茶, a kind of Puer tribute, and did not describe its flavor. In his Puercha Ji 普洱茶記, Ruan Fu (1802-?) comments that "Puer cha was famous nationwide; its taste was most 'strong' (yan 䤄).” The author of the Gongnu Tanwang Lu (宮女談往錄), Jin Yi and Shen Yiling quote one of the palace maids saying that the Empress Dowager Ci Xi preferred drinking Puer tea after eating greasy foods and as an everyday tea during the winter months (she sipped green longjing tea during the summer). These two records allow us to understand why the Qing royal family loved Puer and how its consumption related to seasonal changes, but neither mentioned aged Puer. In 1963, when PRC government cleaned the warehouses in the Forbidden City, two tons of Puer gongcha (貢茶, tribute tea) was found, telling us that Puer was probably considered storable for long periods of time without being discarded for passing its "use-by date.” In summary, no evidence exists to support the idea that drinking aged Puer tea was ever the widespread practice it has become in the past two decades. The only clear description of consuming aged Puer tea is found in Tang Lusun's Zhongguo Chi 中國吃, published in 1976. Tang describes tasting tea made from a hundred-year-old Puer tea round in the home of the son of a former Yunnan provincial official. He had gotten the tea from his father and told Tang that it could be stored long term, and if protected from humidity, it became more flavorful over time. However, Tang did not mention whether, in the early Republican era, drinking aged Puer was popular. ${ }^{4}$

Puer's packaging provides some interesting information. Two small paper cases I collected in Kunming hold compressed squares of Puer tea. They were produced in 1992 and 1997, respectively, and both are marked with an expiration period, one of 18 and the other of 36 months. Some traders think that this simply followed the government regulation that an expiration date had to be listed. Interestingly, packaging produced after the mid-2000s all changed the preservation periods to "long term," indicating the influence of the aged Puer tea fad. Whether the Qing royal family liked to sip aged Puer or not, and no matter what the real story is behind stamping an expiration period on Puer packaging, there is no doubt that the "taste of aging" has become the

\footnotetext{
${ }^{3}$ Different terms were used in different editions to describe how puer tea was made. For example, in the Chengyi ben xinshi biaodian ben 重印程乙本新式標點本 edition (Shanghai: Yadong tushuguan, 1927), men 燗 “simmer over slow fire without allowing evaporation” was used; ao 㥿 ‘simmering’ was used in the Zhiyanzhai siyuegai qixiang jinghui guben 脂硯齋四閱改 七薌精繪古本 edition (chapter 63, Taipei: Wenyuan chubanshe,1959, 1399); and pao 泡 “steeping” was used in the Chengbingben Xinjuan quanbu xiuxiang 程丙本新鎸全部繡像 edition (Taipei: Guangwen shuju,1977).

${ }^{4}$ In a separate paper (Yu 2010), I analyze in more detail why the taste of aged tea, chennian, was not a common tasting category in Ming and Qing times.
} 
most significant consumption category and reference of value over the last 10 years.

When discussing the relationship between the appearance of aging and social nostalgia, Appadurai (1996) reminds us that "The patina of objects takes on its full meaning only in a proper context." This is also the case with respect to the taste of aged Puer. Since the effects of aging on the flavor of tea have been known for a long time, why did it take Puer's entry into Taiwan's tea culture for the "taste of aging" to become a uniquely popular tasting category? How does this development relate to Taiwan's historic, cultural, and economic contexts?

Puer became familiar to Taiwanese in relation to the gradual opening between Taiwan and China in late 1980s. As China began to open her doors to the outside world and Taiwan allowed her citizens to visit their hometowns in the mainland, the so-called China Fever (zhongguo re 中國熱, the Taiwanese desire to learn about and experience China), at that time provided a bump to Puer's acceptance in Taiwan. The first exchanges between the two sides of the Taiwan Strait helped create a Taiwanese longing for Chinese goods, especially those having historical and vernacular flavors. Chinese local specialties, handicrafts, and antiques began to be imported to Taiwan. Probably because Puer was closely identified with aging, aged Puer tea tended to be sold in Taiwan's antique shops. Some tea merchants also enthusiastically organized tasting events to introduce Puer to tea lovers. Because Puer could not be legally imported, whether from Yunnan or Hong Kong, before 2004, shuttle traders were kept busy traveling between Taiwan and Hong Kong.

Another expression of China Fever, collecting Yixing purple-sand stoneware tea pots was a fad closely related to Taiwan's tea culture. Tea pots made by famous Yixing potters enjoyed high prices in the early 1990s. The prices often skyrocketed to hundreds of thousands a piece, and when the market collapsed in the mid-1990s, it left Taiwanese merchants eager to search for alternatives_-Puer was soon identified as a potential target.

Taiwan's contemporary tea art culture also played a key role. It had emerged in the mid-1970s as Taiwan's tea industry shifted from an export-orientation to focusing mainly on the domestic market (Hsu, 2005). To encourage domestic consumption, Taiwan's government went to great lengths to promote Woolong tea production for domestic consumers by way of organizing tea art activities and tea competitions to encourage improvements in tea quality. Tea houses combining a traditional literati air with a youthful hipness also emerged in 1980s, and these drew younger generations into tea tasting. A tea art culture developed around Taiwan's popular Woolong teas and a style of tea ritual similar to that from Chaozhou—using a small tea pot and a few cups to serve guests for a few rounds-which figures significantly in both Taiwan's modern material culture and aesthetics. New designs for tea utensils, arrangements, and refined tea ritual performance, along with an infusion of creativity in organizing tea gatherings, have all made steeping and tasting a cup of tea widely recognized as an elegant event. Taiwan's society has gradually come to perceive tasting tea as not merely drinking a popular everyday drink, but a cultural event for which one must be particular about space, tea, water, utensils, music, and mood, as well as tasting attentively. We can see what Elias (1978) called a “civilizing process" taking place in Taiwan's developing tea culture, which is gradually becoming integrated into the everyday lives of Taiwanese families.

In contrast to Hong Kong's less developed tea-tasting culture, Taiwan's sophisticated tea-tasting community has been fertile ground for the aged Puer tea fad. A famous Hong Kong tea merchant explained to me that until recently Hong Kong's tea culture has been very much limited to restaurant teahouses, where the emphasis is on small dishes (similar to Spanish tapas) rather than tea, and Puer has had a long local history as 
the tea everyone consumed daily, therefore the aged tea held no special attraction for Hong Kong residents. This made the Hong Kong tea merchants look to Taiwan as a potential market. In turn, the "taste of aging" was allowed to be developed into a fatal attraction in the context of Taiwan's tea art culture.

Taiwan's tea culture also provided fertile ground for developing the criteria of judging aged Puer. In the late 1980s and early 1990s, Taiwanese tea merchants and experts made great effort to explore the quality of Puer teas and discover their appreciable flavors. They had to figure out the right way to taste the aged Puer, so they could persuasively present it as a desirable commodity to their discerning customers. This was only possible because in the early days there were still sufficient supplies of diverse kinds of aged Puer to make such exploring affordable. Taiwan's tea community had a golden opportunity to taste and compare different kinds of aged Puer and define what constituted a "good" and "authentic" flavor. They established a tasting standard, which although never explicitly published, was enough to evaluate and help market aged Puer. One tea shop owner remembered that in the early 1990s, he and his colleagues would gather at the shuttle trader's place when the aged Puer was brought back from Hong Kong, to try out different kinds of the tea. Through careful tasting and comparing various kinds of "antique Puer," they were able to reach consensus in establishing certain evaluation criteria. Now that the price of aged Puer has skyrocketed to such incredible levels, the same could never be done today, he added.

The tea merchants' development of a style and standard of tasting and evaluating aged Puer tea was effectively spread to consumers through the publication of books and journals, special tea events and internet discussions, all of which encouraged people to adopt categories such as the flavor of aging, mouth feel, and the circulation of $q i$ by which to experience and judge the qualities of Puer. Thanks to the tea's reputed medicinal qualities, these matters of judgment extended to burping and sweating, which are seen as positive bodily reactions. As a system for appreciating, identifying, and authenticating the value of aged Puer was gradually established through Taiwan's already refined tea tasting culture, "age” became a recognized criterion of value and the Puer tea fad arose from this foundation.

It is especially interesting that Taiwan aficionados developed “pure dry-storage” (chun gancang 純乾倉) as a category for good quality aged Puer. This label indicates that Puer's aging should proceed in a dry "natural" environment, rather than the artificially wet conditions often used by Hong Kong merchants to expedite aging. Even though Hong Kong merchants do not accept this criterion and stress that Hong Kong's humid weather does not permit this kind of storage, the Taiwan market still considers "pure dry-storage" as the ideal condition for clean storage, natural aging, and thus authentic "old” Puer tea, in contrast to the tea kept in artificially wet storage, which can cause negative effects and even health concerns. This insistence reflects that the above-mentioned discourse of "historical coincidence" (instead of intentional stockpiling) in Puer's life history is crucial to Taiwan's definition of the taste of aging stressing the authentic flavor of aged Puer should develop from natural or non-manipulated storage conditions. Despite Hong Kong merchants' objection, this "pure dry-storage” discourse spread at least to Yunnan and Beijing, as it has become a distinctive category that tea traders pay attention to judging Puer with a clean, authentic taste.

Whether Taiwanese insistence about proper storage is meaningful in practical terms or not, the ideal "taste of aging” without a doubt became the steppingstone across which the craze for aged Puer spread. Once the "pure dry-storage" model was defined as the standard for authentic, clean, safe, and appreciable aging of the tea, other methods were criticized as artificial or simply wrong. Even if stockpiling these days is "historically 
intentional," its goal is to reproduce the ideal flavor derived from historical contingency, and the thousands of tons of Puer stored in warehouses in various parts of the world are aging towards this goal. Hence, since the value system around Puer is grounded in this ideal principle, the Puer fad can continue to develop and expand on the basis of this subjective tasting category, which, for market purposes, is an "objective" standard nonetheless. Creating this standard has been Taiwan's greatest contribution to the globalization of Puer tea consumption.

In the mid-1990s, the Puer tea fad expanded across China, and newly produced tea became the focus. As a result, Taiwan's influence in the Puer market has declined sharply. With the amount of aged Puer dwindling due to its continuous consumption, the largest remaining quantities are held by a few big collectors. Nowadays little aged Puer circulates on the market. As the Puer trade has shifted from aged Puer to newly produced tea, Guangdong and Yunnan have emerged as new centers of the global trade. Despite the fact that Taiwan no longer plays an important role in the Puer market, the "taste of aging" idea created in Taiwan has continued to affect and support Puer's globalization.

\section{In Retrospect}

Taiwan's role in the globalization of Puer tea demonstrates that the anthropological framework of globalization versus localization does not always hold. This suggests that we need to more closely examine how each player performs to understand variation in the globalization process. The historical contingency (as the Taiwan tea merchants refer to it) is striking: Taiwan's tea art provided fertile ground for a Puer fad to emerge in a new consumption area, and this fad based its expansion on a new tasting standard and value system established by this new Puer area.

Due to limited space, this paper only analyzes Taiwan's role in the aged Puer tea fad of mid-1990s and does not give an account of subsequent the contributions Taiwan (and China and Korea) have made to Puer's globalization since the late 1990s. Merchants conceived of taking Taiwan's high-mountain tea to Yunnan, for instance, which brought about today's big-tree (or old-tree) tea fad. This is another important chapter in Puer's globalization, but it will have to be addressed in another paper.

Although this paper examines only one phase of Puer's globalization, it points to the fact that cultural flows of taste and sensory experience are an important dimension of globalization. In his famous book, Modernity at Large: Cultural Dimensions of Globalization (1996), Appadurai discusses globalization in terms of five dimensions - ethnoscapes, mediascapes, technoscapes, financescapes, and videoscapes. The Puer tea case shows that we may need to add another dimension, "tastescape" or better, "sensescape," that is, cultural flows of taste or sensory experience. These categories of experience are often associated with metaphors (e.g., Puer's "taste of aging," order, cleanliness, and comfort) that give rise to what I would call a sensescape that is transmitted through media and commodity chains cross-nationally or cross-culturally. Global fashions and fads emerge with the global circulation of sensescapes that allow consumers in different societies to make sense of information carried by brand names and commodities. As flows of information and commodities become more efficient, exchanges and the sharing of culturally specific categories of taste and sensory experience also become more globalized. Nonetheless, as we see with the case of Puer tea as we look into its globalization, we should pay more attention to how different players introduce changes to the process, changes that are often more than mere popularization, resistance, or localization of a particular scape. 


\section{References}

Cao, Xueqin (1927). Hongloumeng 紅樓夢 (The dream of red chamber). Chengyi ben xinshi biaodian ben 重印程乙本新式標 點本 edition. Shanghai: Yadong tushuguan.

Cao, Xueqin (1959). Hongloumeng 紅樓夢 (The dream of red chamber). Zhiyanzhai siyuegai qixiang jinghui guben edition 脂 硯齋四閱改七薌精繪古本, chapter 63. Taipei: Wenyuan chubanshe.

Cao, Xueqin (1977). Hongloumeng 紅樓夢 (The dream of red chamber). Chengbingben Xinjuan quanbu xiuxiang edition 程丙 本新鎸全部繡像. Taipei: Guangwen shuju.

Li, Yuanyang (1997). Jiajing Dali Fuzhi 嘉靖大理府志 (Jiajing Gazetteer of Dali Fu). V.2. Microfilm in The Fu Ssu-nien Library, based on Ming Jiajing 42th year version from Palace Museum Taipei.

Ruan, F (Qing time). Puercha ji 普洱茶記 (The record of pue tea). In Dianbi 滇筆 (A note of Yunnan). Rare edition in Beijing National Library.

Xie, Zhao-zhi (2003). Dianlüe 滇略. Vol. 3. In Zhongguo Xinan Wenxian Congshu 中國西南文獻叢書 (Issue 3, The series of literature from China's south-east).Vol. 11. Lanzhou: Lanzhoudaxue Chubanshe.

Appadurai, A. (1996). Modernity at large: Cultural dimensions of globalization. Minneapolis: University of Minnesota Press.

Bestor, T. (2001). Supply side shushi: Commodity, market, and the global city. American Anthropologist, 103(1), 76-95.

Chatao huyi gongzuoshi (Ed.). (2001). Puer Wenxuan. 普洱文選 (Selected articles of puer study). (Additional edition). Taipei: Chatao huyi wenhua gongsi.

Chi, Zongxian (2004). Woolong Tea. Taipei: Yuhe Wenhua.

Deng, Shihai (1995). Puercha 普洱茶 (Puer tea). Taipei: Fuzhungtian Zazhishe.

Elias, N. (1978). The civilizing process: The history of manners. (E. Jephcott, Trans.). Oxford: Basil Blackwell.

Fan, Zengping (1994). Puercha zai taiwan de chuanbo yu fazhan. 普洱茶在台灣的傳播與發展 (The spread and development of Puer ta in Taiwan). In Huang Shuguei (Ed.), Zhongguo Puercha Wenhua Yanjiou: Zhongguo Puercha Guoji Yantaohuei Lunwenji, 中國普洱茶文化研究: 中國普洱茶國際研討會論文集 (Research of China's puer tea: proceedings of international conference on China’s puer tea). (pp. 72-86). Kunming: Yunnan keyi chubanshe.

Hsu, Xianyao (2005). Taiwan Baozhongcha Lunji 臺灣包種茶論集 (collective articles on Taiwan’s baozhong tea). Taipei: Lequn Shuju.

Jin, Yi, \& Chen, Yiling (1991). Gongnü Tanwanglu 宮女談往錄 (records of palace maids’ memories of the past). Beijing: Zijincheng Chubanshe.

Katsuhiko, H. (1999). The eternal tree: Searching for the origines of tea in Yunnan. Tokyo: Toho Shobo Publishers.

Lei, Pingyang (2003). Puer Cha Ji 普洱茶記 (a record of Puer tea). Taipei: Yingyi Tangren Gongyi Chubanshe.

Tang, Lusun (1976). Zhongguo Chi 中國吃 (eating Chinese Food). Taipei: Dadi Chuban Gongsi.

Watson, J. (Ed.). (1997). Golden arches east: McDonald's in East Asia. Stanford, California: Stanford University Press.

Yu, Shuenn-Der (2010). Materiality, stimulants and the Puer tea fad. Journal of Chinese Dietary Culture, 6(1), 107-142.

Zheng, Tiantian (2011) Karaoke bar hostesses and Japan-Korea wave in post socialist China: Fashion, cosmopolitanism and globalization. City \& Society, 23(1), 42-65. 